\title{
Reply to letter to the editor: Medical physics workforce modelling: do we need what we want?
}

\author{
Claire Dempsey ${ }^{1}$ \\ Published online: 6 August 2018 \\ (c) Australasian College of Physical Scientists and Engineers in Medicine 2018
}

I thank Professors Van Dyk and Battista for their commentary on this editorial [1,2]. I completely agree that activitybased modelling is paramount to determine staffing needs of the current and future workforce and that equipmentbased models do not consider the wider roles of a medical physicist nor that different staffing levels may be appropriate for different departments. Analysis of F2000 values with department specific data indicates that departments with essentially the same equipment profiles have widely varying F2000 staff calculations. For example: departments with 6 linacs and an HDR service in Australasia had F2000 values ranging from 9.5 to 21.4 qualified physicists. In reality, the departments at the extremes of this range had 6 and 8.4 qualified medical physicists respectively.

The editorial was written to highlight how staffing levels (both calculated via F2000 [3] and actual) have changed overall in Australasia over the last decade. This was done by comparing medical physicist numbers with the simplified F2000 model that had been previously used for workforce analysis, and is still the standard for state and federal governments of Australia. It was an "apples to apples" approach that was intended to start the discussion across Australasian departments, as it is clear that the simplified model is not suitable, and even the full F2000 model is in need of review.
I also thank Professors Van Dyk and Battista for providing an excellent set of additional references that should be included as part of an Australasian-based workforce modelling evaluation. With thorough examination of models from other countries it is hoped that we can generate a realistic and locally-focussed interpretation that can be provided to administrators and governments in order to update their understanding of medical physics staffing standards. This recognition will be a much needed leap forward for the profession in Australasia, both now and into the future.

\section{References}

1. Dempsey C (2018) Medical physics workforce modelling: do we need what we want? Australas Phys Eng Sci Med. https://doi. org/10.1007/s13246-018-0663-6

2. Van Dyk J, Battista JJ (2018) Letter to the editor: Medical Physics Workforce Modelling: Do we need what we want? Australas Phys Eng Sci Med (in press)

3. Oliver L, Fitchew R, Drew J (2001) Requirements for radiation oncology physics in Australia and New Zealand. Australas Phys Eng Sci Med 24:1-18
This reply refers to the comment available online at https://doi. org/10.1007/s13246-018-0663-6.

\section{Claire Dempsey}

claire.dempsey@calvarymater.org.au

1 University of Newcastle, Callaghan, NSW, Australia 